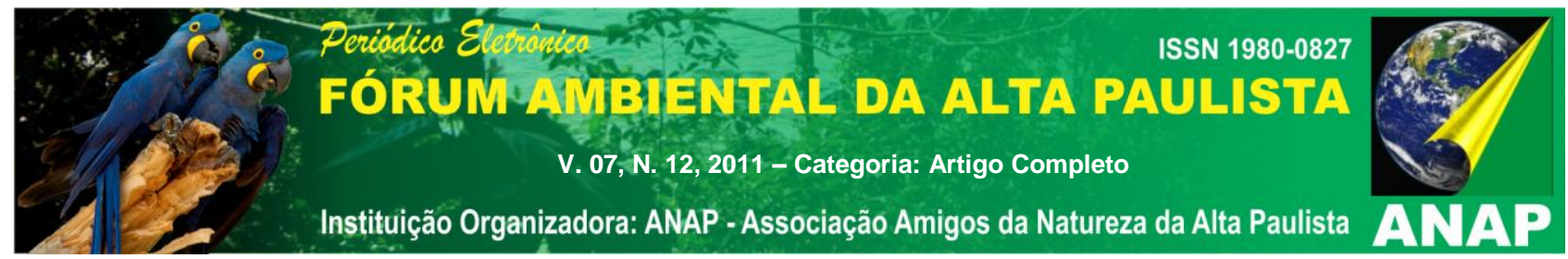

\title{
TECNOLOGIAS DE REMEDIAÇÃO DE SOLOS
}

Flávio Fernando Manzini ${ }^{1}$

Kaoara Batista de Sá ${ }^{2}$

\section{Lídia Maria de Almeida Plicas ${ }^{3}$}

\section{Altair Benedito Moreira ${ }^{4}$}

Resumo: Atualmente, devido ao considerável aumento populacional e consequente necessidade de maior produção de alimentos, tem-se incrementado, também, o investimento em tecnologias para a remediação de solos contaminados, em especial, por metais potencialmente tóxicos oriundos, principalmente, da disposição inadequada de resíduos industriais. Esses contaminantes não se restringem apenas aos solos. Podem ser carreados para os mananciais de águas superficiais ou conduzidos, pela infiltração das águas, aos mananciais subterrâneos. Neste trabalho, procurou-se apresentar as principais metodologias, em uso, para recuperação de áreas degradadas por solos assim contaminados.

Palavras chave: solos contaminados, metais pesados, técnicas de remediação

\subsection{INTRODUÇÃO}

O desenvolvimento de tecnologias de remediação para a contaminação dos solos tem se tornado alvo de pesquisas recentes. Para que seja feito o estudo da descontaminação de uma área há a necessidade de realização de uma identificação

\footnotetext{
1 Doutor em Geologia Regional, Instituto de Biociências, Letras e Ciências Exatas, UNESP-SP fmanzini@ibilce.unesp.br

${ }^{2}$ Bacharel em Química Ambiental, Instituto de Biociências, Letras e Ciências Exatas, UNESP-SP kaoara@hotmail.com

3 Doutora em Físico-Química, Instituto de Biociências, Letras e Ciências Exatas, UNESP-SP plicas@ibilce.unesp.br

${ }^{4}$ Doutor em Química Analítica, Instituto de Biociências, Letras e Ciências Exatas, UNESP-SP

altair@ibilce.unesp.br
} 


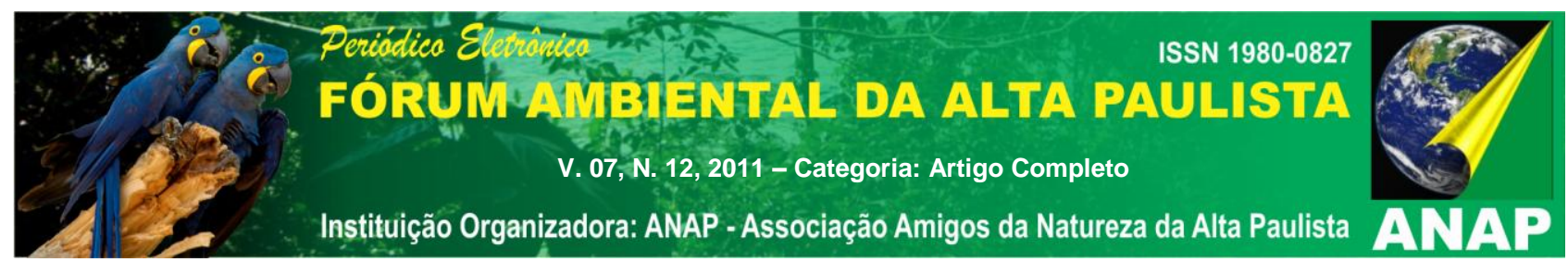

(inventário) e de um diagnóstico da evolução e do tratamento desta área (CASTELOGRANDE et al., 2007).

Uma forma de classificação dos métodos de descontaminação baseia-se no local de aplicação do tratamento. Assim, tem-se a descontaminação "in-situ" (i.e., realizada no local) e a descontaminação "ex-situ" (i.e., realizada fora do local). Atualmente em todo o mundo, a tendência é a de se utilizar as técnicas de remediação in situ, por apresentarem custo menor e não provocarem contaminações secundárias, fato observado na remediação ex situ, já que ocorre o transporte do material contaminado até o sítio de tratamento (TAVARES, 2009). Outras formas de classificação levam em consideração a ação de remediação, como biológica, físico-química, térmica e técnicas especiais envolvendo eletrocinética e plasma (SPARKS \& CORN, 1993 apud CASTELO-GRANDE et al., 2007).

As principais tecnologias para o tratamento de solos contaminados por metais são a lavagem do solo, a técnica do plasma, o transporte de sólido, a solidificação/estabilização, a fitorremediação e a remediação eletrocinética (PEDRAZZOLI, 2004).

\subsection{DESENVOLVIMENTO}

Esta pesquisa foi realizada através de consultas à bibliografia pertinente, na forma de livros e periódicos específicos. O meio eletrônico também foi utilizado como suporte, nesta compilação. Esse estudo constituiu parte de um trabalho maior, que foi apresentado à UNESP, como Monografia de Conclusão do Curso de Bacharelado em Química Ambiental.

\subsubsection{LAVAGEM DE SOLO (“SOIL FLUSHING”)}

É uma técnica de descontaminação de solos que consiste na extração dos contaminantes através da dissolução, da suspensão em soluções aquosas ou de reação química com o fluido que se encontra nas camadas dos solos. Promove a remoção de compostos orgânicos, inorgânicos, metais e substâncias radioativas. Se aplicado ex-situ, 


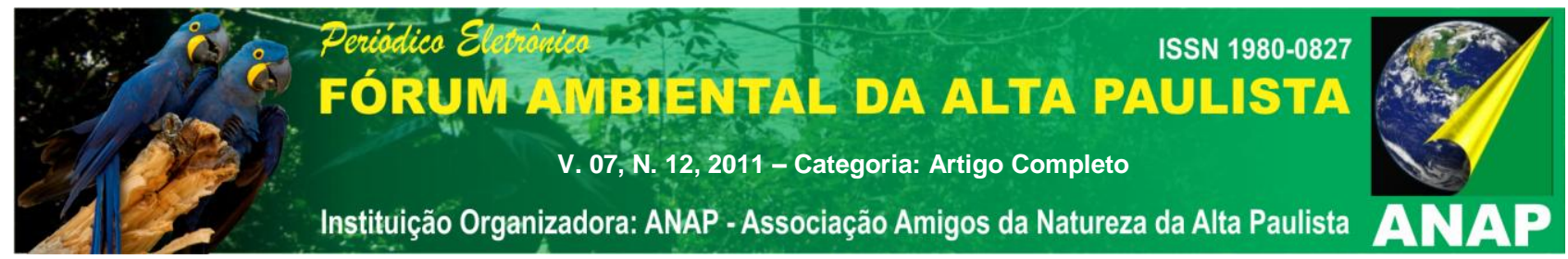

pode ser considerado um pré-tratamento, reduzindo a quantidade de solo contaminado a ser processado por outras tecnologias de remediação (SMITH et al., 1993 apud CASTELO-GRANDE et al., 2007).

É normalmente aplicada in-situ (DENNIS et al., 1992 e GRIFITHS, 1995 apud CASTELO-GRANDE et al., 2007). Por meio de furos de injeção, de galerias que promovem a infiltração ou por pulverizadores colocados à superfície (Figura 01), o fluido é aplicado e, portanto, os contaminantes são arrastados pela água. A água, posteriormente, é bombeada à superfície e recolhida em poços de extração para que seja sujeita ao tratamento (ROOTE, 1997; FIÚZA, 2002 e SPARKS \& CORN, 1993 apud CASTELOGRANDE et al., 2007).

Quando essa técnica é aplicada ex-situ segue as etapas de escavação, de fragmentação, de separação granulométrica, de lavagem das diferentes frações e de decisão sobre o destino dos resíduos finais (lama). Essa lama pode ser depositada em aterros sanitários ou, quando muito contaminada, ser submetida a tratamentos específicos dependendo do contaminante (p.ex. extração por solvente, solidificação ou vitrificação) (CASTELO-GRANDE et al., 2007). A eficácia da remoção pode ser aumentada utilizando-se aditivos, como nitrato de cobre, cádmio ou chumbo (ANJOS \& MATTIAZZO, 2001).

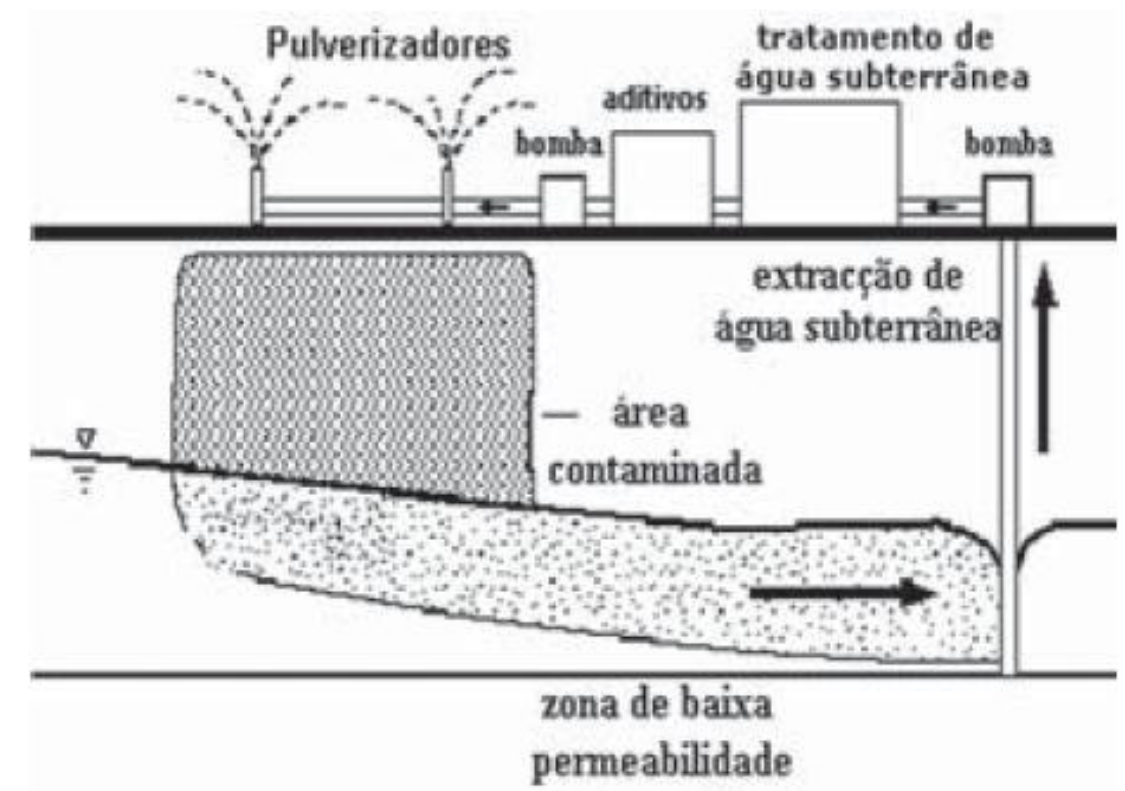




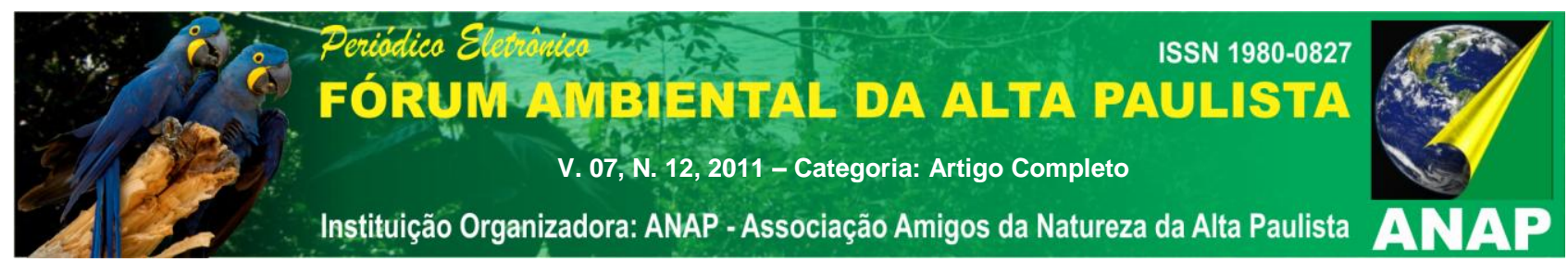

Figura 01: Esquema simplificado da técnica in-situ de lavagem de solo (CASTELOGRANDE et al., 2007).

\subsubsection{TÉCNICA DO PLASMA}

Nesta tecnologia de remediação de solos, um gás é aquecido a temperaturas extremas, que podem alcançar até $100.000^{\circ} \mathrm{C}$, para que seja criado o plasma. Ao se aproximar o solo contaminado do plasma criado, ocorre o seu aquecimento a temperaturas muito elevadas, e extinguem-se as moléculas de oxigênio. Nessas condições ocorrem a vitrificação dos compostos inorgânicos, como metais e radicais reativos, e a degradação dos compostos orgânicos. Por vezes, é necessário um segundo tratamento após o plasma, pois pode haver a combustão incompleta de alguns produtos e a formação de dioxinas e furanos (CASTELO-GRANDE et al., 2007).

É uma metodologia de descontaminação de solos que se tem revelado a mais eficaz das tecnologias térmicas, sob o ponto de vista energético. Tem-se mostrado muito viável para o tratamento de misturas de resíduos, lamas e sólidos, porém, parece não ser muito eficiente quando os contaminantes são sais, pois esses compostos são dificilmente imobilizados pela vitrificação (VITALE et al., 1997 apud CASTELO-GRANDE et al., 2007). Outra limitação é o fato de se tratar de procedimento ex situ.

\subsubsection{SOLIDIFICAÇÃO/ESTABILIZAÇÃO}

Esse processo consiste na modificação das características físicas e químicas do resíduo, visando a sua imobilização. Os metais são remediados, normalmente, através da solidificação ex-situ por encapsulamento ou complexação, porém, essa tecnologia tem sido adaptada para aplicações in-situ, uma vez que se torna mais barata quando aplicada a volumes maiores de solo, em profundidade maior. Entretanto, essa técnica não parece ser uma solução muito duradoura e segura, pois não extrai o metal do solo, somente o imobiliza podendo, inclusive, reverter 0 processo e liberar os contaminantes (PEDRAZZOLI, 2004 e TAVARES, 2009). 


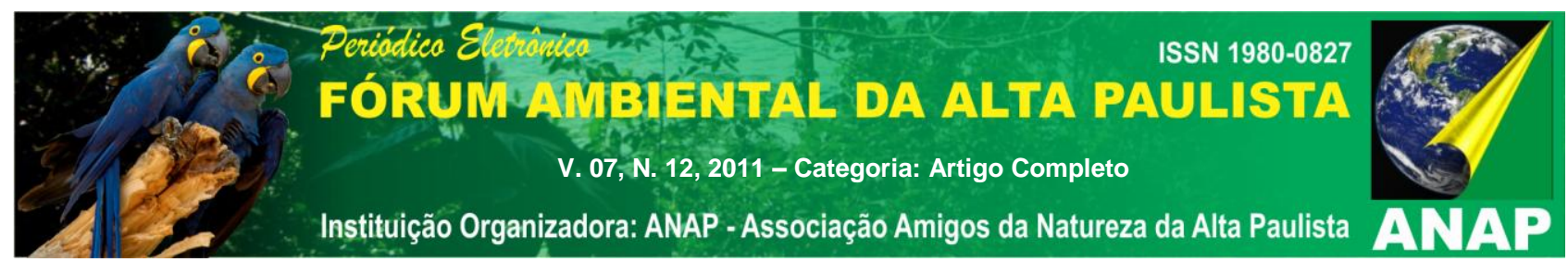

A vitrificação é uma outra técnica de solidificação que envolve a passagem de uma corrente elétrica entre eletrodos, resultando na retenção de sólidos e a incorporação de metais no produto vitrificado. Essa técnica tem sido usada na captura de mercúrio e de metais voláteis, como chumbo e arsênio (US ENVIRONMENTAL PROTECTION AGENCY - EPA, 1994 apud PEDRAZZOLI et al., 2003).

A Tabela 01 apresenta um resumo dessa técnica de remediação.

\subsubsection{TRANSPORTE DE SÓLIDOS}

É a extração de metais do solo (Tabela 02), através do uso de água ou outras soluções aquosas. Ácidos e complexantes são melhor empregados na extração ex-situ, porém não têm muita praticidade para a remediação in-situ (DOD, 1994 apud PEDRAZZOLI et al., 2003).

\subsubsection{FITORREMEDIAÇÃO}

A fitorremediação é uma técnica de remediação de solos que consiste no uso de plantas e da microbiota, associada ou não a adições de amenizantes de solo, e a práticas agrícolas que têm como objetivo a extração, o seqüestro ou a diminuição da toxicidade de contaminantes (SALT et al., 1998 apud SANTOS \& RODELLA, 2007). Esse tipo de remediação tem sido descrita como efetiva, não destrutiva, econômica e é socialmente aceita (ALKORTA \& GARBISU, 2001 apud SANTOS \& RODELLA, 2007). Portanto, representa uma alternativa ecológica aos métodos mais convencionais de remediação de solos, tais como a escavação e remoção da camada de solo contaminado e a posterior disposição em aterros e a lavagem do solo (MEAGHER, 2000 apud SANTOS \& RODELLA, 2007).

Tabela 01: Resumo da tecnologia de solidificação/estabilização. 


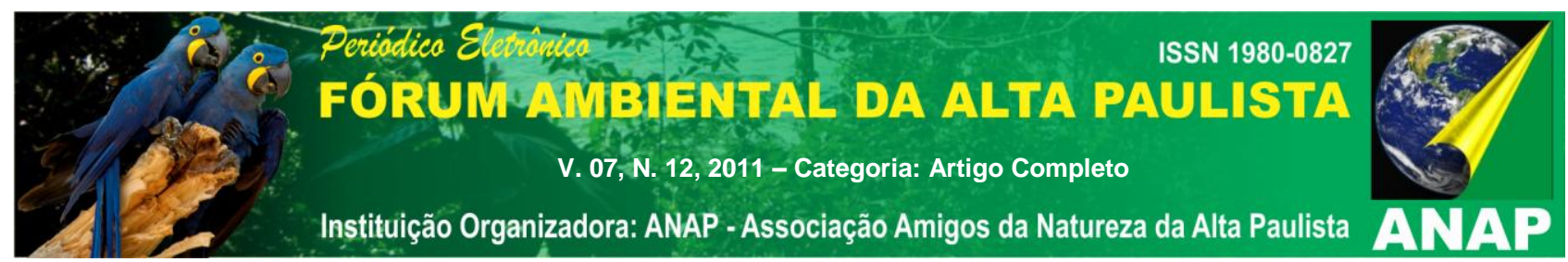

\section{Características Gerais}

Disponivel comercialmente

O custo é influenciado pela profundidade do contaminante, o grau de homogeneidade do solo, a presença de fragmentos e a presença de umidade.

\begin{tabular}{cc}
\hline Reagente baseado na estabilização In Situ & Vitrificação \\
\hline $\begin{array}{c}\text { Descrição: Adição de reagentes com ou sem } \\
\text { aditivos para fisicamente ou quimicamente } \\
\text { converter contaminantes em forma menos } \\
\text { móvel. }\end{array}$ & $\begin{array}{c}\text { Descrição: Uso de energia para dissolver o solo } \\
\text { e fisicamente e quimicamente encapsular } \\
\text { contaminantes com menos mobilidade e forma } \\
\text { mais estável. }\end{array}$ \\
\hline Estado da arte: Comercial & Estado da arte: Comercial; uma empresa \\
está licenciada.
\end{tabular}

Fonte: EPA, 1997 apud Pedrazzoli, 2004.

A fitorremediação ocorre por dois processos básicos, a fitoextração e a fitoestabilização (PEDRAZZOLI, 2004).

A fitoextração consiste no transporte de metais do solo para o tecido vegetal sobre o solo, e a sua posterior destruição. A semente por apresentar maior produção de biomassa, parece ser o elemento mais promissor no hiperacúmulo de metais em vegetais. Testes preliminares têm sido feitos para estimular a absorção do cádmio. Em relação ao chumbo, apesar do pouco resultado até então obtido, é muito provável que, em solos modificados, a incorporação deste metal, seja facilitada, pelas plantas (PEDRAZZOLI, 2004). 


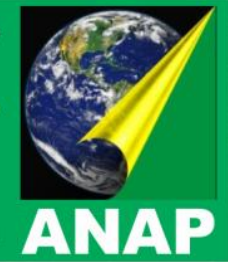

Tabela 02: Resumo da tecnologia de transporte de sólidos.

\section{Características Gerais}

- $\quad$ Melhor empregado em solos com alta permeabilidade.

- Diferentes sistemas de transferência capazes de introduzir soluções de transporte.

- O custo primário é influenciado pela necessidade de potencial para o refreamento, a profundidade de contaminação e o tempo exigido para operação.

Risco de contaminação associado ao aqüífero com solução transporte não recuperada que contem contaminantes solubilizados, melhor empregado em locais com aqüiferos que tem baixos campos específicos.

Transporte de água

\section{Transporte de reagente}

\begin{tabular}{ll}
\hline $\begin{array}{l}\text { Descrição: Uso de água para solubilizar os } \\
\text { contaminantes antes da extração. }\end{array}$ & $\begin{array}{l}\text { Descrição: Uso de reagentes químicos } \\
\text { para solubilizar os contaminantes para } \\
\text { extração. }\end{array}$ \\
\hline Estado da arte: Comercial. & Estado da arte: Pesquisa limitada.
\end{tabular}

Aplicabilidade: Cromo (VI), potencialmente Aplicabilidade: Escala de bancada: aplicado para outros metais solúveis em chumbo e urânio.

água.

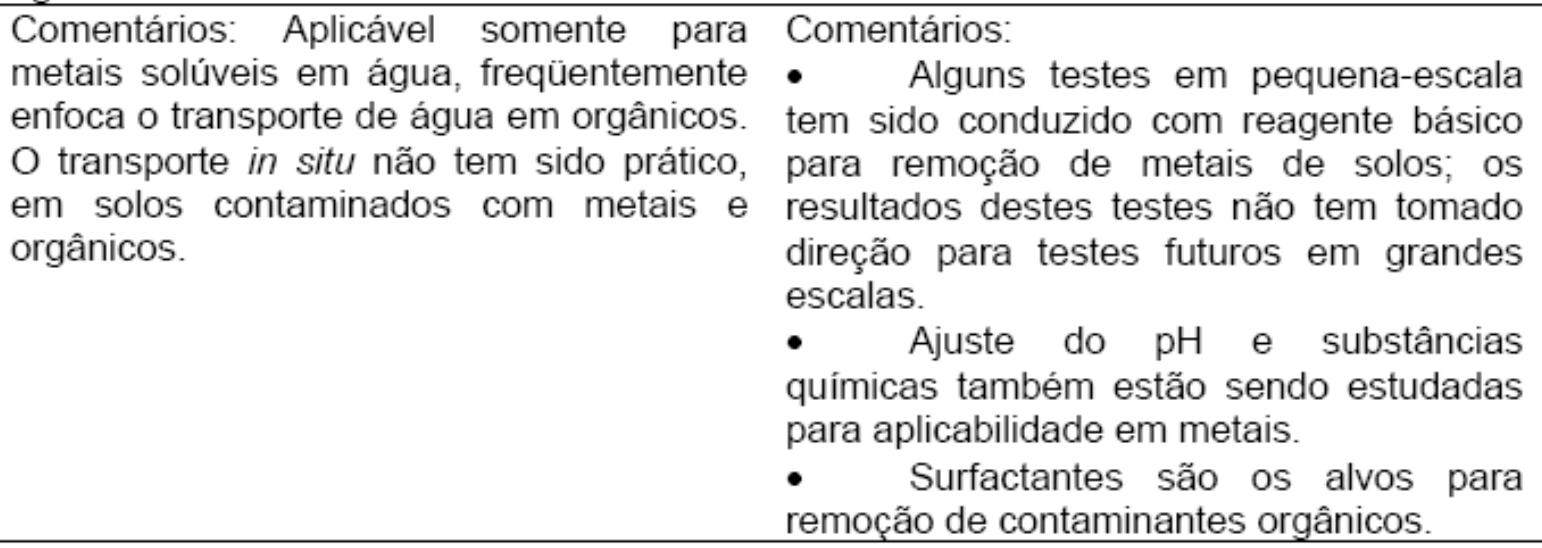

Fonte: EPA, 1997 apud Pedrazzoli, 2004.

A fitoestabilização ocorre devido à secreção, pelas plantas, de compostos que afetam o pH do solo e, assim, por meio de processos de precipitação, de complexação, de humificação e de lignificação, ocorrem a diminuição da mobilidade e a solubilidade dos metais, prevenindo a entrada de contaminantes nas águas subterrâneas e na cadeia alimentar (ACCIOLY \& SIQUEIRA, 2000 apud SANTOS \& RODELLA, 2007).

As plantas também contribuem para o controle da erosão do solo e da diminuição da lixiviação devido ao aumento da evapotranspiração. Essa técnica, portanto, reduz o risco pela estabilização dos metais próximos à superfície do solo, porém apresenta um 


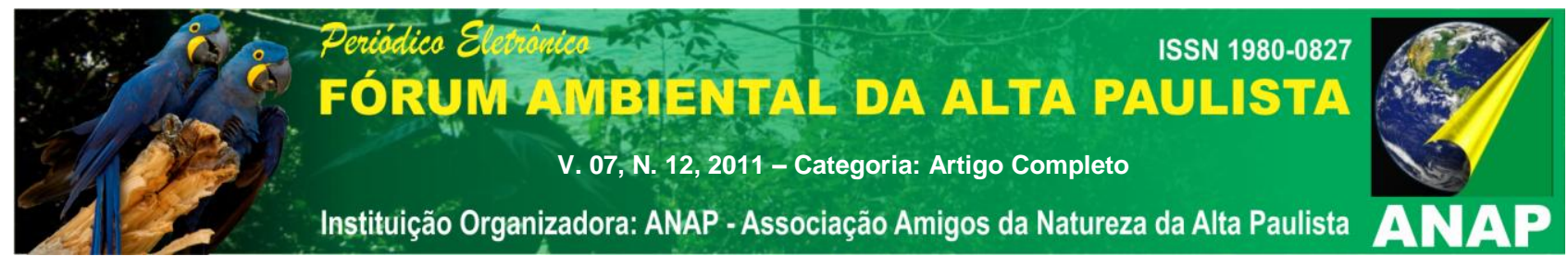

baixo potencial para o chumbo (CUNNINGHAM \& BERTI, 1993 apud PEDRAZZOLI et. al., 2003). A Tabela 03 apresenta um resumo desta técnica.

A fitorremediação parece adaptar-se melhor à remediação de locais onde ocorreu a contaminação dispersa dos metais, em baixas concentrações e nos horizontes mais superficiais (PEDRAZZOLI, 2004).

Relacionados à fitorremediação há, também, os amenizantes de solos, que são materiais adsorventes e imobilizadores dos metais pesados presentes, e que são muito empregados em solos com diferentes níveis de contaminação, pois facilitam a revegetação de áreas contaminadas (CONNER, 1990 e CLEMENTE et al., 2003 apud SANTOS \& RODELLA, 2007). Esses amenizantes podem ser os corretivos de acidez, de fosfatos, de óxidos de ferro e de manganês e de materiais orgânicos. Esses últimos afetam a disponibilidade dos metais pesados e estão relacionados a vários fatores, como a natureza da matéria orgânica, a degradabilidade, o teor de sais, o efeito no pH do solo, o potencial redox, o tipo de solo no qual será aplicado e o metal alvo (ROSS, 1994 e SHUMAN, 1999 apud SANTOS \& RODELLA, 2007).

Tabela 03: Tipos de tecnologia de fitoremediação: vantagens e desvantagens.

\begin{tabular}{|c|c|c|}
\hline $\begin{array}{c}\text { TIPOS DE } \\
\text { FITOREMEDIAÇÃO }\end{array}$ & VANTAGENS & DESVANTAGENS \\
\hline \multirow[t]{2}{*}{ Fitoextração pelas árvores } & Alta produção de biomassa & $\begin{array}{c}\text { Eficiente para migração off-site } \\
\text { e deixa transportar metais } \\
\text { para a superficie. }\end{array}$ \\
\hline & & $\begin{array}{c}\text { Metais estão concentrados na } \\
\text { biomassa da planta }\end{array}$ \\
\hline \multirow[t]{2}{*}{ Fitoextração pela grama } & Alta acumulação & $\begin{array}{l}\text { Baixa produção de biomassa e } \\
\text { lenta taxa de crescimento. }\end{array}$ \\
\hline & & $\begin{array}{c}\text { Metais estão concentrados na } \\
\text { biomassa da planta }\end{array}$ \\
\hline \multirow[t]{2}{*}{ Fitoextração pela safra } & $\begin{array}{l}\text { Alta biomassa e aumento da } \\
\text { taxa de crescimento }\end{array}$ & $\begin{array}{c}\text { Alta ameaça na cadeia } \\
\text { alimentar através da ingestão } \\
\text { por herbívoros. }\end{array}$ \\
\hline & & $\begin{array}{c}\text { Metais estão concentrados na } \\
\text { biomassa da planta }\end{array}$ \\
\hline Fitoestabilização & $\begin{array}{l}\text { Não precisa da disposição da } \\
\text { biomassa contaminada }\end{array}$ & $\begin{array}{l}\text { Permanecendo a } \\
\text { responsabilidade na questão, } \\
\text { incluindo a manutenção por } \\
\text { um período indefinido de } \\
\text { tempo (refreamento em vez de } \\
\text { remoção) }\end{array}$ \\
\hline
\end{tabular}




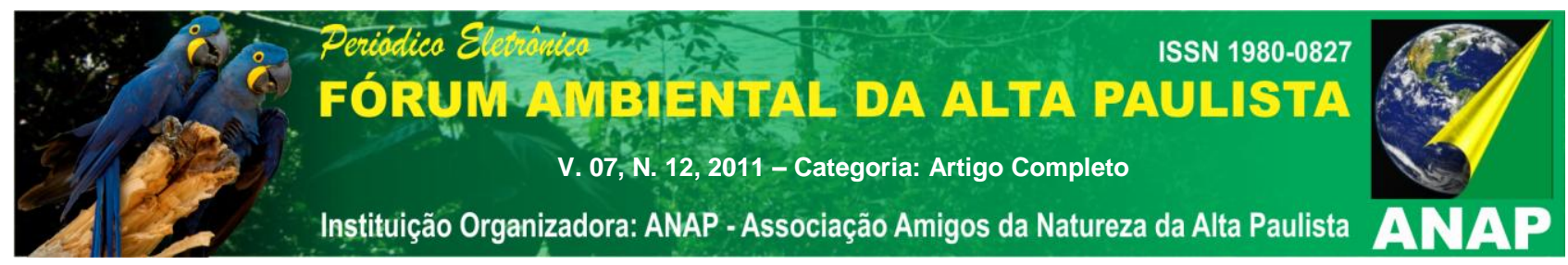

Fonte: EPA, 1997 apud Pedrazzoli, 2004.

A turfa pode ser considerada um material orgânico muito promissor na fitorremediação de solos, pois é naturalmente rica em substâncias húmicas (que são as responsáveis pela elevada capacidade de adsorção de metais) e encontra-se amplamente distribuída, a baixo custo, em todo o território nacional (FRANCHI et al., 2003 apud SANTOS \& RODELLA, 2007).

A incorporação do material orgânico no solo, de modo geral, auxilia o processo de revegetação, pois melhora a estrutura e a retenção de umidade no solo, e fornece macro e micro nutrientes. A matéria orgânica também interfere, positivamente, no ciclo de vários nutrientes, atuando na complexação e quelação de metais, o que proporciona a redução da disponibilidade dos mesmos, diminuindo a toxicidade para as plantas (LOGAN, $1992 \mathrm{e}$ SHUMAN, 1998 apud SANTOS \& RODELLA, 2007).

\subsubsection{REMEDIAÇÃO ELETROCINÉTICA}

Esta técnica é, também, denominada processamento eletrocinético do solo, ou eletromigração ou, ainda, eletrocorreção. É um método utilizado na extração de metais e outros resíduos orgânicos em solos saturados ou insaturados, lamas e sedimentos (ACAR et al., 1996 apud PEDRAZZOLI et al. 2003; PEDRAZZOLI, 2004). Tem sido considerada promissora, pois apresenta um excelente potencial de recuperação.

A Tabela 04 apresenta um resumo desta técnica.

A tecnologia in-situ é uma técnica de separação e remoção dos contaminantes que pode ser utilizada na extração de metais pesados e de alguns tipos de resíduos orgânicos de solos e sedimentos (RODSAND \& ACAR, 1995 e ACAR, et al., 1995 apud PEDRAZZOLI et al. 2003). Essa metodologia consiste na aplicação de uma corrente contínua e de baixa intensidade entre eletrodos, nos solos. Os eletrodos devem ser constituídos por material inerte, como grafite ou platina. Quando é aplicada a corrente elétrica ocorre a eletrólise da água tornando a solução ácida junto ao anodo. A "frente ácida" do anodo desloca-se até o cátodo por migração, o que leva à dessorção dos contaminantes do solo (CASTELO-GRANDE et al., 2007). Desta maneira, são mobilizados na forma de íons ou partículas (COSTARRAMONE et al., 1998 e YU et al., 


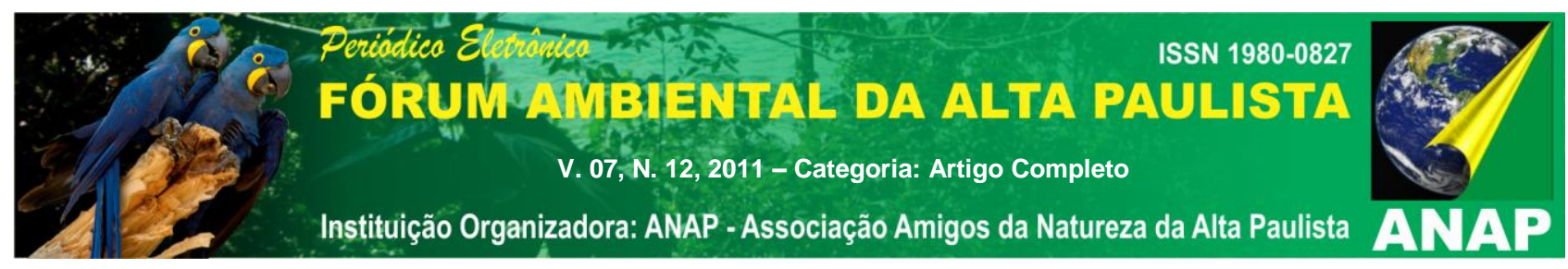

1997 apud CASTELO-GRANDE et al., 2007; PEDRAZZOLI, 2004; GUARACHO et al., 2005).

Em alguns casos, a extração pode ser diretamente dos íons já na forma de metal por um processo que utiliza resina de troca iônica. Essa técnica de remediação também pode ser utilizada na prevenção ou retardamento da migração dos contaminantes, pois os direciona para pontos específicos, evitando que alcancem os freáticos ou aqüíferos (PEDRAZZOLI, 2004). Esse processo é utilizado especialmente na remediação de solos contaminados e que apresentem baixa permeabilidade (COSTARRAMONE et al., 1998 e YU et al., 1997 apud CASTELO-GRANDE et al., 2007; PEDRAZZOLI, 2004). A descontaminação pode ser realizada através dos processos de eletromigração (transporte de espécies químicas carregadas sob um gradiente elétrico), de eletroosmose (de fluido intersticial sob um gradiente elétrico), de eletrólise (reações químicas associadas com o campo elétrico) e de eletroforese (partículas carregadas sob um gradiente elétrico) onde o campo elétrico gerado mobiliza as espécies carregadas eletricamente, as partículas e os íons (RODSAND \& ACAR, 1995 apud PEDRAZZOLI et. al. 2003).

Tabela 04: Análise da tecnologia da remediação eletrocinética. 


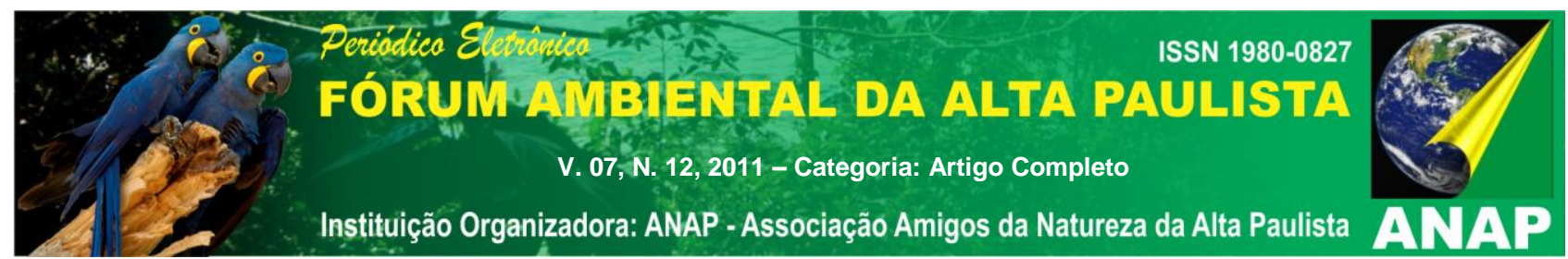

\section{Características Gerais}

A disposição do eletrodo depende da profunddade do solo. Aplicado em solos homogêneos com alta permeabilidade.

\begin{tabular}{c|c}
\hline Remoção Acentuada & Tratamento sem remoção \\
\hline Descrição: & Descrição:
\end{tabular}
eletrodo polarizado, portanto faz-se o acúmulo de contaminantes e posteriormente a remoção e o tratamento ex situ.

A freqüência com que a polaridade do eletrodo é invertida está determinada pela taxa de transporte dos contaminantes através do solo.

Transporte eletro-osmótico de contaminantes através de zonas de tratamento localizadas entre os eletrodos. A polaridade dos eletrodos é invertida periodicamente, consequentemente é invertida a direção dos contaminantes.

\section{Estados da arte:}

Equipamentos de alto padrão são encontrados na

Europa. Os últimos estudos de campo estão em andamento nos Estados Unidos.

Aplicabilidade:

Escala piloto: chumbo, arsênio, níquel, mercúrio, cobre, zinco.

Escala de laboratório: chumbo, cádmio, cromo, mercúrio, zinco, ferro, magnésio, urânio, tório, rádio.

As aplicações em escala máxima ainda não foram avaliadas por completo.

\section{Estados da arte:}

Demonstrações estão em andamento.

\section{Comentários:}

A eficiência e o custo efetivo das técnicas não tem sido completamente avaliadas na escala máximas nos Estados Unidos por qualquer agência federal. O EPA, DOE, DOD e o Instituto de Pesquisa de Força Elétrica estão realizando estudos no setor sobre a estimativa de custo. A técnica primária requer adição de água para manter a corrente elétrica e facilitar a migração,

entretanto existe trabalho em andamento para aplicação desta tecnologia em solos parcialmente saturados.

Fonte: Pedrazzoli, 2004.

O uso de surfactantes ou reagentes aumenta a taxa de remoção dos contaminantes nos eletrodos e intensifica esses processos (PEDRAZZOLI, 2004).

A Figura 02 apresenta, esquematicamente, o procedimento. 

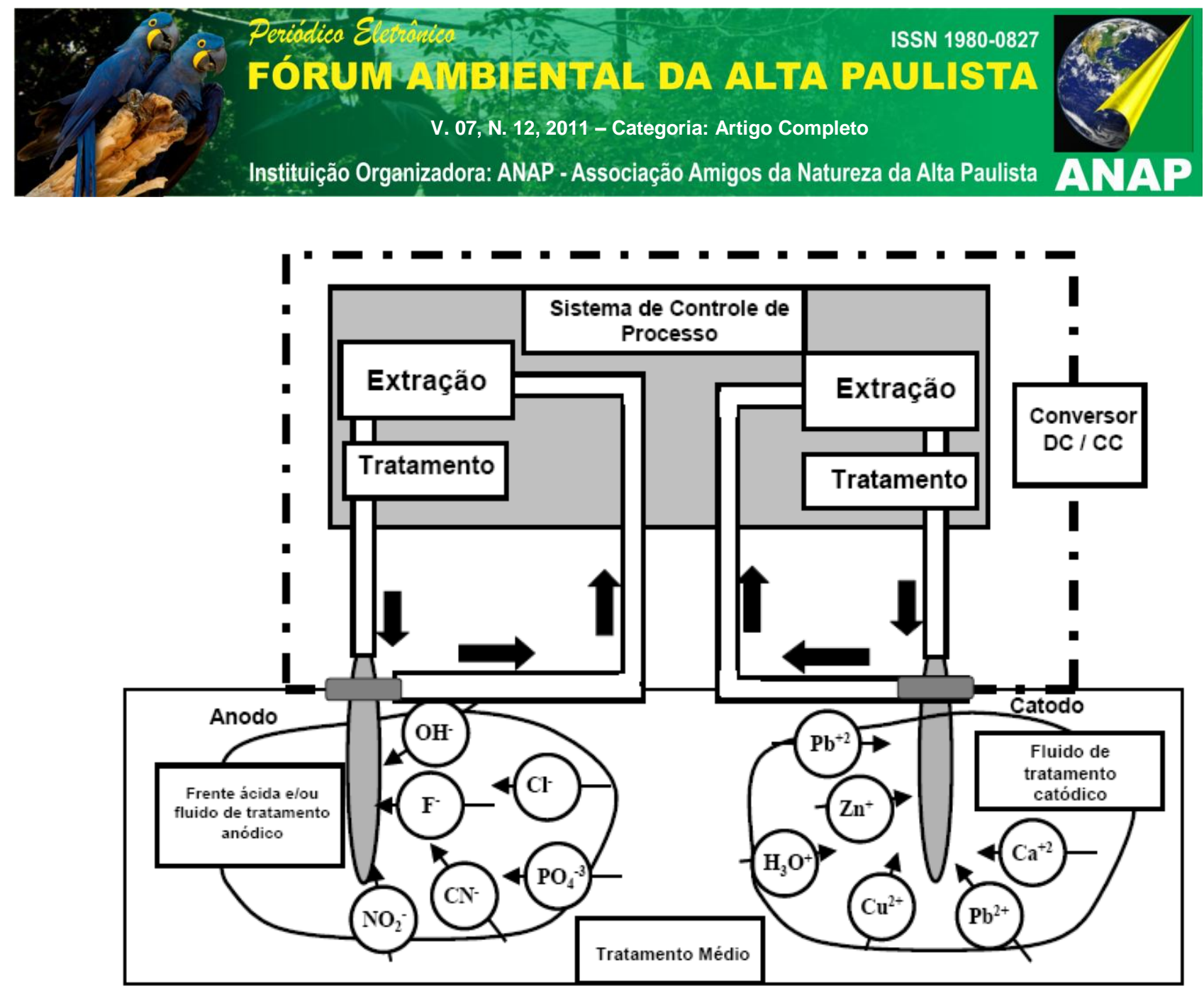

Figura 02: Diagrama esquemático da aplicação típica da remediação eletrocinética (EPA, 1995 apud PEDRAZZOLI, 2004).

Por meio da redução no catodo, pela precipitação e co-precipitação, pelo bombeamento próximo ao eletrodo ou por resinas de troca iônica, os contaminantes são removidos no processo de migração e, posteriormente, tratados pelos processos convencionais (resinas de troca iônica ou eletrodeposição) (WALLMANN, 1994 e PEDRAZZOLI et al. 2003). Na região do anodo, há o aumento da acidez, que cria uma frente de acidez que irá migrar na direção do catodo, favorecendo as reações paralelas de dessorção dos contaminantes que liberam os íons metálicos que serão removidos pela migração (PEDRAZZOLI, 2004 e GUARACHO et al., 2005).

Essa técnica é especialmente eficiente em solos que contenham alta concentração do contaminante alvo. Solos de baixa permeabilidade e média granulometria apresentam uma eficiência entre 75 e 95\% de remoção de chumbo, cromo, cádmio e urânio em níveis de até 2.000 ppm (PEDRAZZOLI, 2004). 


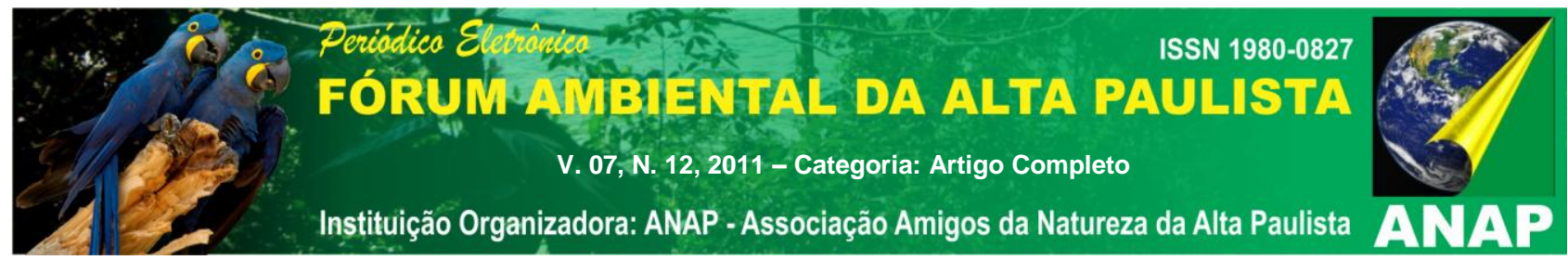

A argila atrai e adsorve fortemente os metais pesados e outras espécies carregadas. Os mecanismos de adsorção desses metais, a complexação da superfície e a troca iônica, dependem dos adsorventes, pois esses apresentam diferentes seqüências de seletividade para diferentes metais. O chumbo, por exemplo, é fortemente atraído e adsorvido por diferentes tipos de argila. Pesquisadores da Universidade do Estado de Louisiana (USA) estudaram a remoção de 2.000 ppm de chumbo agregado à caolinita, obtendo uma eficiência de remoção entre 90 e 95\% (PEDRAZZOLI, 2004).

Esta técnica de remediação, para a remoção in situ de altas concentrações de metais pesados é mais apropriada para pequenas áreas (PEDRAZZOLI, 2004).

\subsection{CONCLUSÃO}

Fatores como o estado (fase de desenvolvimento da tecnologia), a ordem dos metais tratados (quantidade de metais tratados pela tecnologia), o maior fator limitante (questões que podem interferir no uso da tecnologia) e considerações específicas do local (características do solo e profundidade dos contaminantes, que afetam na eficiência da tecnologia) foram utilizados no Quadro 01, para a comparação entre as tecnologias de remediação de solos por eletrocinética, fitorremediação, transporte de sólido e solidificação/estabilização, pois são as metodologias mais utilizadas na remediação in situ de um solo contaminado.

Com base em todo o trabalho desenvolvido, aparentemente, remediar um solo contaminado por meio de fitorremediação parece ser, ainda, a tecnologia mais eficaz. Os motivos dessa premissa são:

- a possibilidade de liberação dos contaminantes durante o procedimento de solidificação/estabilização

- a tecnologia de transporte de sólidos apresenta melhor resultado quando utilizada ex situ

- até o momento, a remediação eletrocinética tem apresentado melhores resultados quando aplicada em áreas pequenas 


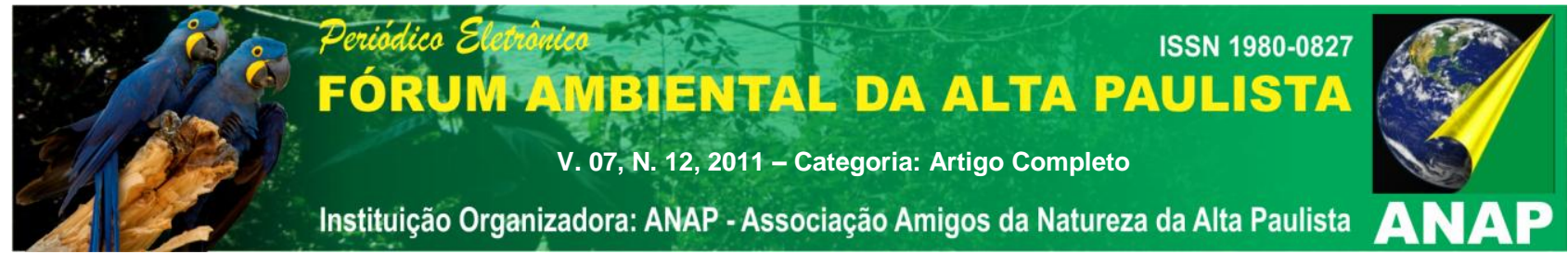

De acordo com Tavares (2009), as vantagens de se tratar um solo contaminado por meio de fitorremediação são:

- até o ano de 2000 eram conhecidas cerca de 400 espécies de plantas acumuladoras, com destaque para a mostarda-da-índia, canola, girassol e alfafa, todas de manejo simples e com ampla disseminação. Com certeza, esse número é bem maior, atualmente. Também, a obtenção de plantas transgênicas tem despontado como uma das alternativas de aumentar o potencial de remediação das plantas;

- baixo custo de operação sem necessidade de gastos ou com gastos irrisórios com energia;

Quadro 1: Análises das tecnologias in-situ para remediação em solos contaminados com metais.

\begin{tabular}{|c|c|c|c|c|}
\hline $\begin{array}{l}\text { Fatores de } \\
\text { Avaliação }\end{array}$ & Eletrocinética & $\begin{array}{l}\text { Fitorreme- } \\
\text { diação }\end{array}$ & $\begin{array}{c}\text { Transporte no } \\
\text { Solo }\end{array}$ & $\begin{array}{l}\text { Solidificação/ } \\
\text { Estabilização }\end{array}$ \\
\hline Estado & $\begin{array}{c}\text { Aplicações de } \\
\text { escala completa } \\
\text { na Europa }\end{array}$ & $\begin{array}{c}\text { Escala piloto. } \\
\text { Atualmente } \\
\text { sendo testada } \\
\text { no campo em } \\
\text { Nova Jersey e } \\
\text { Ohio (USA), na } \\
\text { Finlândia } \\
\text { (Europa) e em } \\
\text { Chernobyl } \\
\text { (Ucrânia) }\end{array}$ & $\begin{array}{l}\text { Comercial. } \\
\text { Selecionado em } \\
\text { diversos locais }\end{array}$ & Comercial \\
\hline $\begin{array}{c}\text { Ordem dos } \\
\text { metais } \\
\text { tratados }\end{array}$ & Amplo & Amplo & Limitado & Amplo \\
\hline $\begin{array}{l}\text { Maior fator } \\
\text { limitante }\end{array}$ & Estado da arte & $\begin{array}{l}\text { Maior tempo } \\
\text { exigido para o } \\
\text { tratamento. } \\
\text { Resultados } \\
\text { reconhecidos e } \\
\text { crescimentos } \\
\text { ajustados }\end{array}$ & $\begin{array}{l}\text { Contaminação } \\
\text { do aqüífero } \\
\text { através do } \\
\text { transporte da } \\
\text { solução residual }\end{array}$ & $\begin{array}{c}\text { Preocupação } \\
\text { com a } \\
\text { integridade do } \\
\text { material em } \\
\text { longo prazo. }\end{array}$ \\
\hline
\end{tabular}




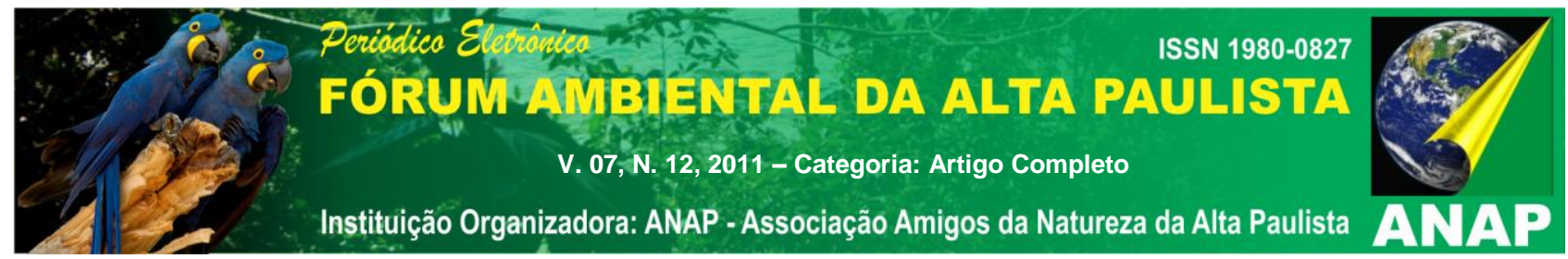

\begin{tabular}{|c|c|c|c|c|}
\hline $\begin{array}{c}\text { Considerações } \\
\text { específicas no } \\
\text { local }\end{array}$ & $\begin{array}{c}\text { Homogeneidad } \\
\text { e no solo. } \\
\text { Nível de mistura } \\
\text { no solo }\end{array}$ & $\begin{array}{c}\text { Profundidade } \\
\text { de } \\
\text { contaminação. } \\
\text { Concentração } \\
\text { da } \\
\text { contaminação }\end{array}$ & $\begin{array}{c}\text { Permeabilidade } \\
\text { do solo. } \\
\text { Fluxo aquático } \\
\text { e profundidade }\end{array}$ & $\begin{array}{c}\text { Fragmentos. } \\
\text { Profundidade } \\
\text { de } \\
\text { contaminação }\end{array}$ \\
\hline
\end{tabular}

Fonte: Pedrazzoli, 2004 (com modificações).

- aplicável in situ possibilitando a reutilização do solo;

- aplica-se a grande variedade de poluentes, podendo remediar vários contaminantes simultaneamente, incluindo metais, pesticidas e hidrocarbonetos;

- consiste em técnica de baixo impacto estético, limitando as perturbações ao meio ambiente se comparado a outras tecnologias (que utilizam tráfego pesado e escavações);

- plantas podem ser mais facilmente monitoradas do que, por exemplo, microorganismos, sendo que muitas espécies vegetais são capazes de se desenvolver em solos cujas concentrações de contaminantes são tóxicas para os microorganismos;

- aplica-se a áreas extensas, onde outras tecnologias são proibitivas;

- acarretam em melhoria da qualidade do solo, no que diz respeito às suas características físicas e químicas, já que aumentam a porosidade, a infiltração de água, fornecem e reciclam nutrientes, além da prevenção da erosão.

De qualquer maneira, mesmo essa tecnologia apresenta limitações, pois a remoção dos contaminantes fica delimitada pela extensão do sistema radicular. É possível, também, que a concentração do contaminante esteja tão elevada que não permitirá o desenvolvimento das plantas. Frente às demais tecnologias, a fitorremediação por vezes, demanda tempo para que se observem os resultados (TAVARES, 2009).

No Brasil, por enquanto, essa tecnologia é pouco utilizada (PIRES et al, 2005, MARTINS et al., 2007 e ROMEIRO et al, 2007, dentre os poucos), mesmo o país possuindo condições climáticas e ambientais favoráveis ao desenvolvimento desse processo. 


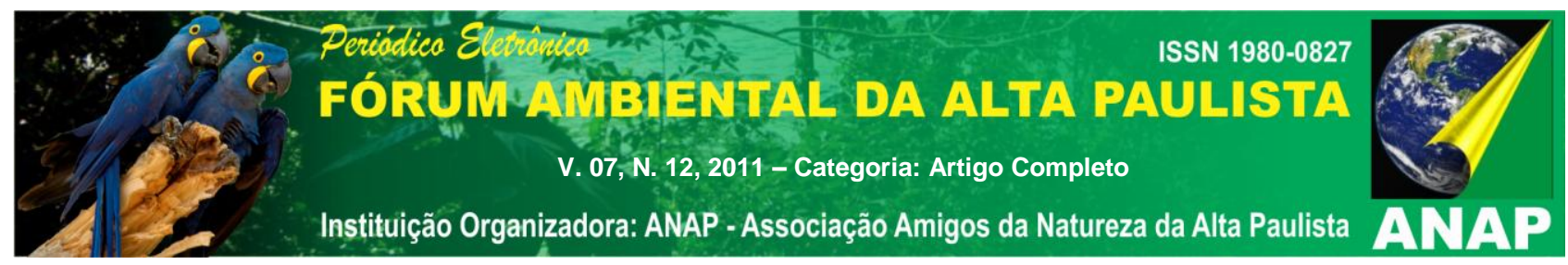

\section{REFERÊNCIAS}

ACCIOLY, A. M. A. \& SIQUEIRA, J. O. Contaminação química e biorremediação do solo. Tópicos em Ciência do Solo, Viçosa, 1:299-351, 2000.

ANJOS A. R. \& MATTIAZZO M. E.; Extratores Para Cd, Cu, Mn, Ni, Pb e Zn em Latossolos Tratados com Biossólido e Cultivados com Milho. Scientia Agrícola, Piracicaba, v. 58, n. 2, p. 337-344, abr/jun 2001.

CASTELO-GRANDE T.; AUGUSTO P. A. \& BARBOSA D. Técnicas de Descontaminação de Solos: uma revisão. Ingenium, série II, no 98, março/abril 2007, p.126-131.

FRANCHI, J. G.; SIGOLO, J. B. \& LIMA, J. R. B. Turfa utilizada na recuperação ambiental de áreas mineradas - metodologia para avaliação laboratorial. R. Bras. Geoc., São Paulo, 33:255-262, 2003.

GUARACHO V. V.; PONTE M. J. J. S.; ADAMOSKI L. F. \& OLIVEIRA, M. Utilização da Técnica de Remediação Eletrocinética para Remoção de Chumbo e Níquel de Solos de Landfarming de Refinaria de Petróleo. In: CONGRESSO BRASILEIRO DE P \& D EM PETRÓLEO E GÁS, 3, 2005, Salvador, Ba. Anais... Salvador, 2005

MARTINS, A. P. L.; ReISSMANN, C. B., FAVARETtO, N., BOEGER M. R. T. \& OliVEIRA E. B. Capacidade da Typha dominguensis na fitorremediação de efluentes de tanques de piscicultura na Bacia do Iraí - Paraná. Revista Brasileira de Engenharia Agrícola e Ambiental, Campina Grande, v.11, n.3, p.324330, 2007.

PEDRAZOLLI C. D.; IRYODA K. I. \& PONTE H. A. Remediação Eletrocinética de Chumbo em Resíduos Industriais. In: ENCONTRO E EXPOSIÇÃO BRASILEIRA DE TRATAMENTO DE SUPERFÍCIES - EBRATS, 11, 2003, São Paulo, SP. Anais... São Paulo, 2003.

PEDRAZZOLI, C. D. Remediação eletrocinética de chumbo em resíduos industriais. Curitiba, 2004. 122p. Dissertação (Mestrado em Engenharia) - Setor de Tecnologia, Universidade Federal do Paraná.

PIRES, F. R.; SOUZA, C. M.; SILVA, A. A.; CECON, P. R.; PROCÓPIO, S. O.; SANTOS, J.B. \& FERRREIRA, L.R. Fitorremediação de solos contaminados com tebuthiuron utilizando-se espécies cultivadas para adubação verde. Planta daninha v.23 n.4 Viçosa out./dez. 2005.

ROMEIRO, S.; LAGÔA, A. M. M. A.; FURLANI, P. R.; ABREU, C. A. \& PEREIRA, B. F. F. Absorção de chumbo e potencial de fitorremediação de Canavalia Ensiformes L. Bragantia, Campinas, v.66, n.2, p.327334, 2007.

SANTOS, G. C. G. \& RODELLA, A. A. Efeito da adição de fontes de matéria orgânica como amenizantes do efeito tóxico de B, Zn, Cu, Mn e PB no cultivo de Brassica juncea. R. Bras. Ci. Solo, Viçosa, v.31, n.4, p.793804, jul/ago. 2007.

TAVARES, S. R. L. Fitorremediação em solo e água de áreas contaminadas por metais pesados provenientes da disposição de resíduos perigosos. Rio de Janeiro, 2009. 371p. Tese (Doutorado em Engenharia Civil) - Universidade Federal do Rio de Janeiro.

WALLMANN, P.C., 1994. "Elecktrokinetic remediation," U.S. Department of Energy, DOE/EM-0138P, Office of Environmental Restoration and Waste Management, Office of Technology Development, Technology Catalogue, 5pp. http://iridium.nttc.edu/env/tmp/008.html. acesso: maio/2011 